\title{
Effect of Home-based Rehabilitation Intervention on Quality of Life of patients with Cerebral Stroke
}

\author{
Javad Jafari ${ }^{1,}$ Fatihe Kerman Saravi ${ }^{2 *}$, Fariba Yaghoubi Nia ${ }^{2}$ \\ 1. Student Research Committee, School of Nursing and Midwifery, Zahedan University of Medical Sciences, Zahedan, Iran \\ 2. School of Nursing and Midwifery, Zahedan University of Medical Sciences, Zahedan, Iran
}

Received: 27 October 2020

Accepted for publication: 4 January 2021

[EPub a head of print-19 January 2021]

Payesh: 2021; 20 (1):81-90

\begin{abstract}
Objective (s): In order to prevent the complications of the disease and improve the quality of life of patients with stroke, home-based care programs could be effective. This study aimed to assess such an intervention.

Methods: This quasi-experimental study was performed on 60 patients with stroke in Zahedan, Iran, in 2019. The intervention group received rehabilitation trainings for three sessions each lasting for 45 minutes. The control group received the usual care. The specific quality of life questionnaire for stroke patients was administered one and three months after the intervention. Data were analyzed using SPSS-22 software performing repeated measures analysis, independent t-test and chi-square.

Results: The mean score of total quality of life in one and three months after the intervention was significantly higher in intervention group compared to the control group $(p<0.001)$. The results of repeated measures analysis of variance regarding the effect of time and group on quality of life and its dimensions showed a statistically significant difference between the two groups $(\mathrm{P}<0.001)$.
\end{abstract}

Conclusion: Home-based rehabilitation intervention could improve quality of life of patients suffering from stroke.

Key Words: Home-Care Rehabilitation, Quality of Life, Cerebral Stroke

\footnotetext{
* Corresponding author: School of Nursing and Midwifery, Zahedan University of Medical Sciences

E-mail: F_kermansaravi@yahoo.com
} 


\title{
تاثير آموزش توانبخى در منزل بر كيفيت زندكى بيماران مبتلا به سكته مغزى
}

\author{
جواد جعفرى'، فتيحه كرمان ساروى '، فريبا يعقوبى نيا' \\ ا. كميته تحقيقات دانشجويى، دانشكده يرستارى مامايى، دانشخاه علوم يزشكى زاهدان، زاهدان، ايران

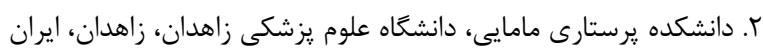

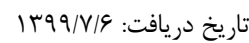

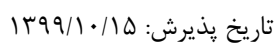

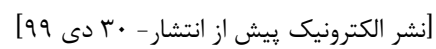

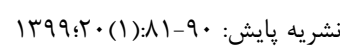

جكيده

مقدمه: جهت يُشگَيرى از عوارض بيمارى و بهبود كيفيت زندگى بيماران مبتلابه سكته مغزى، مى توان از برنامه هاى مراقبتى در منزل اسـتفاده

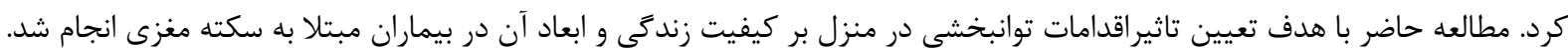

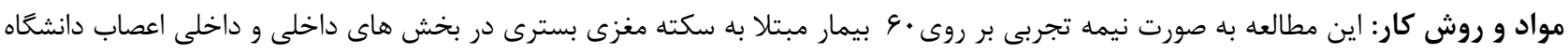

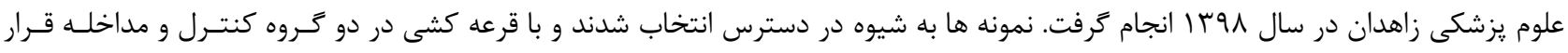

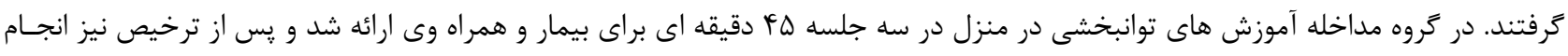

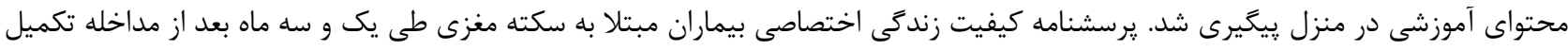

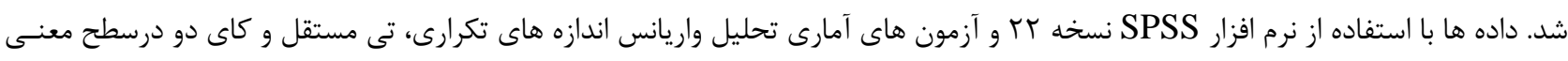

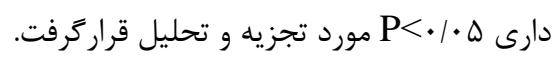

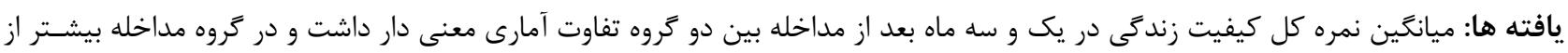

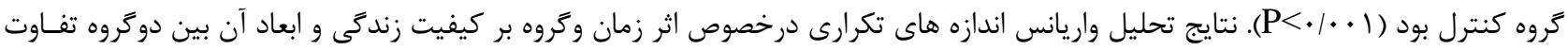

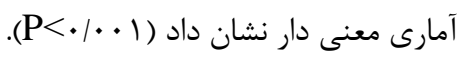

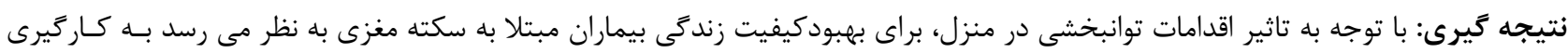

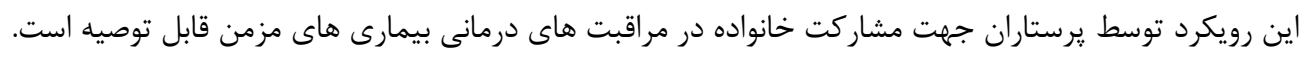

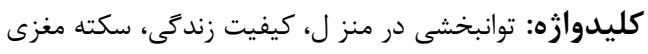


و بهبود كيفيت زندكى بيماران مسى تـوان از برنامـهـ هـاى مراقبتى

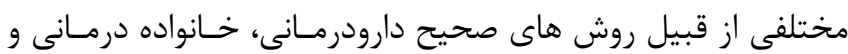

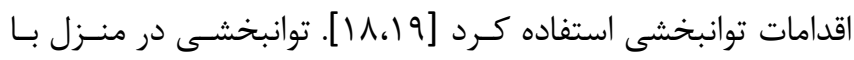

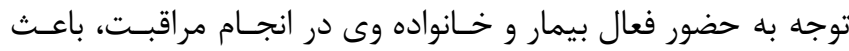

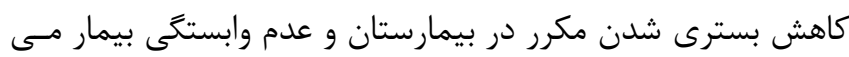

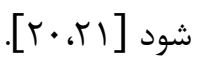
از مزاياى خدمات توانبخشى در منزل ميى توان به ارزان بودان بودن، امكان

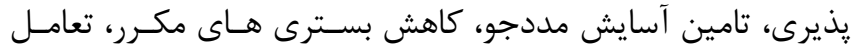

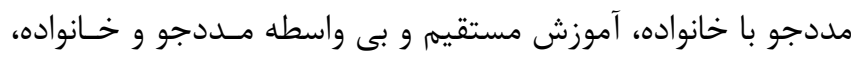

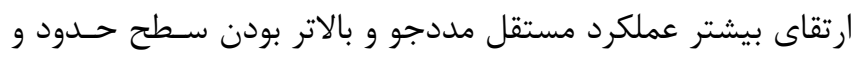

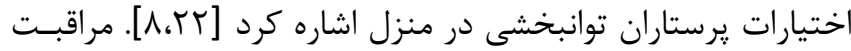

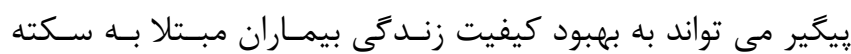

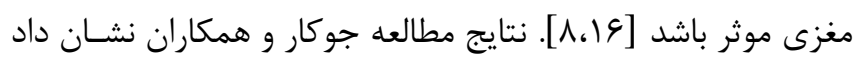

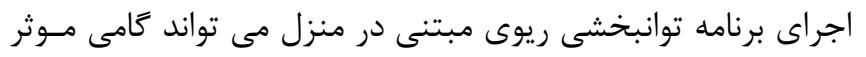

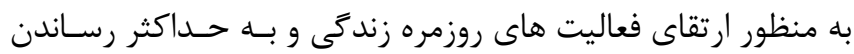

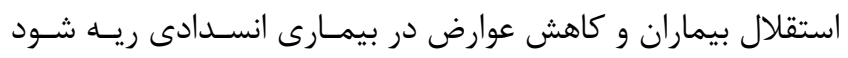

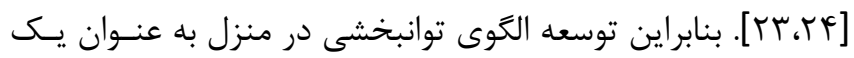

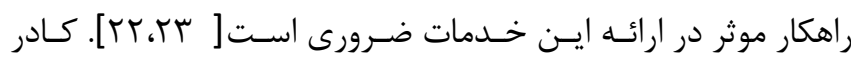

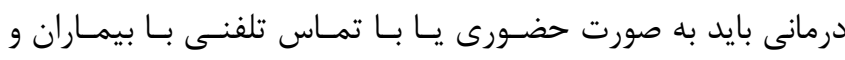

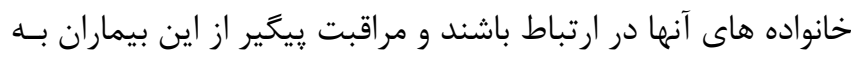

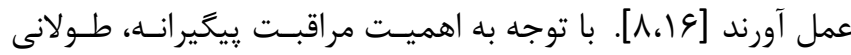

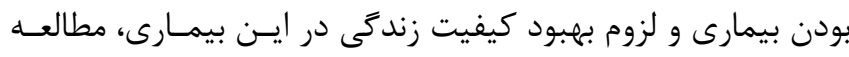

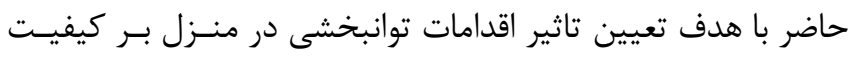

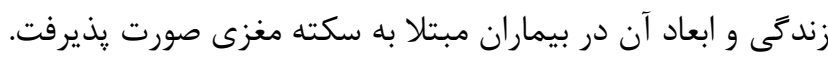

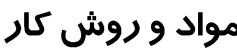

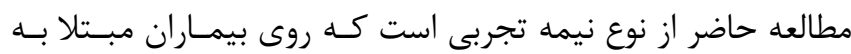

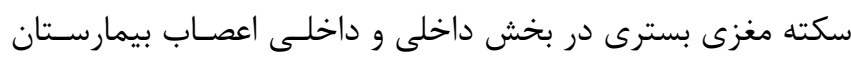

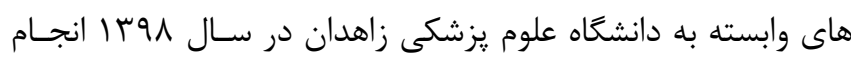

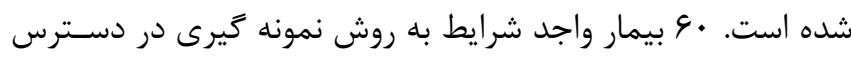

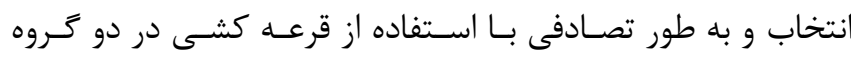

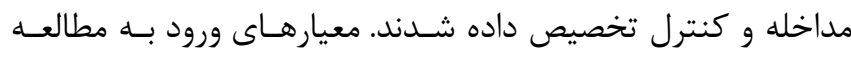
شامل: ابتلا به سكته مغزى از نوع ايسكميك براى اولين بار، ســرى تهرى

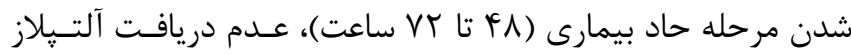

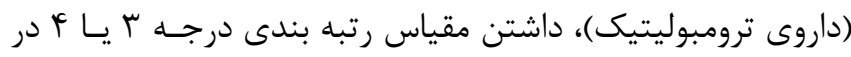

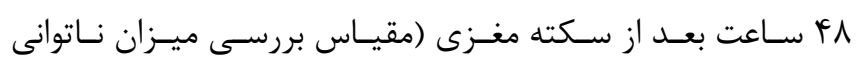

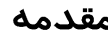

سكته مغزى مههم ترين عامل مرك در جهان و ايران بعـد از بيمـارى

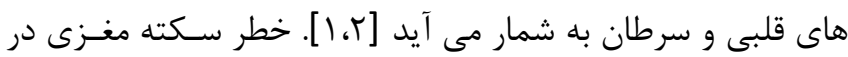

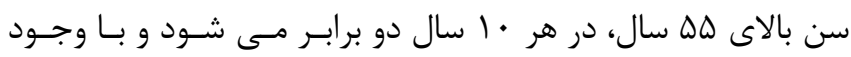

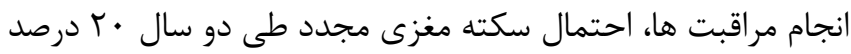

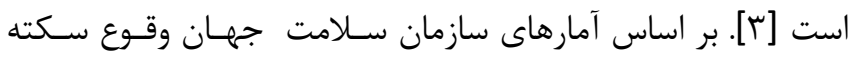

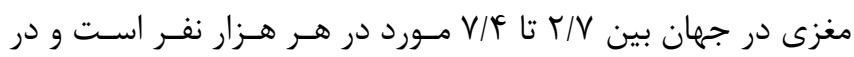
كشورهاى ارويايى شيوع سكته مغزى تقريبا يـك ميليــون در سـال

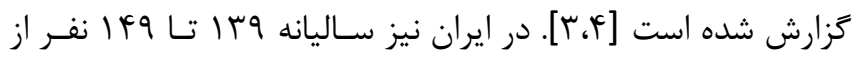

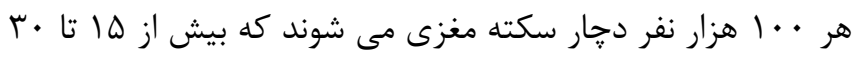

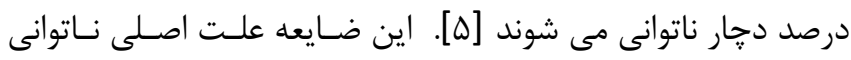
هاى بلند مدت و جدى محسوب مى شود و اولين اخستلال از ميـان

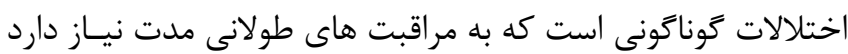

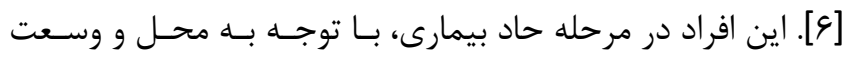
ضايعه دجار نقايص مربوط به ميدان بينايى، حركتى، حسى، كلامسى درى

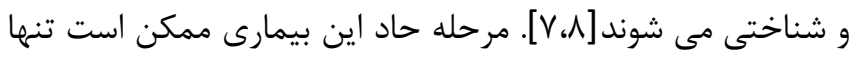

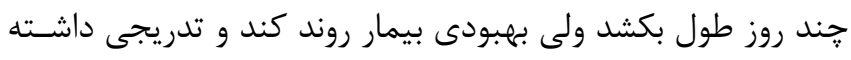

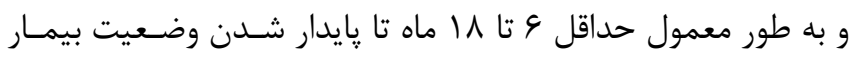
زمان نياز دارد [•، (9.1].

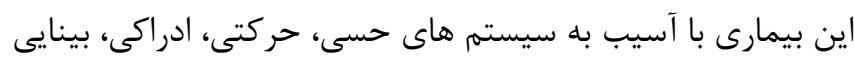

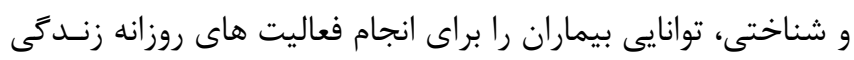

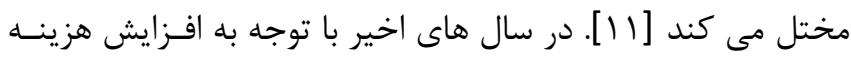

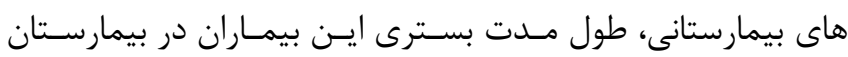

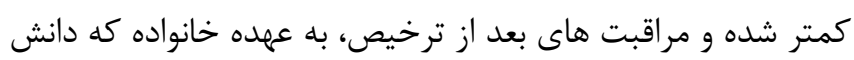

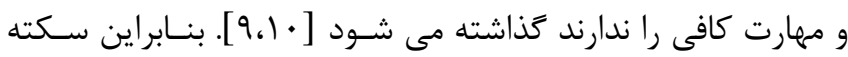

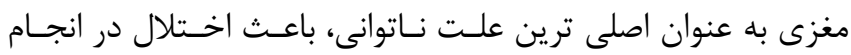

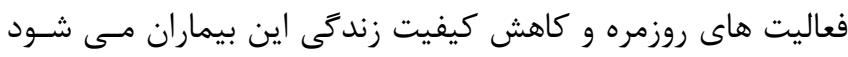

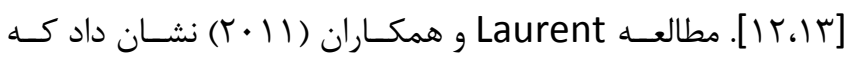

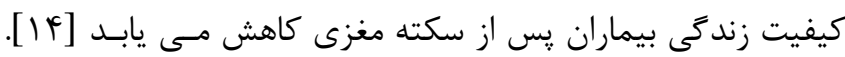

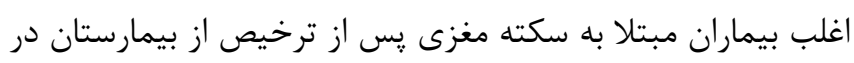

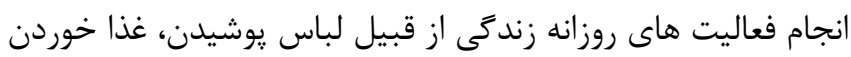

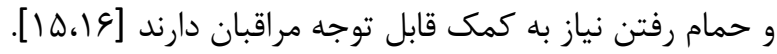

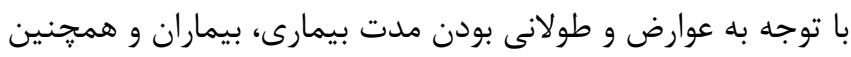

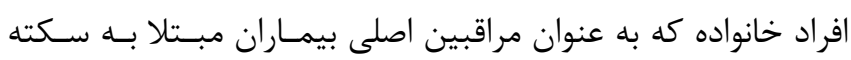

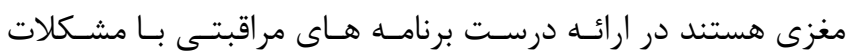

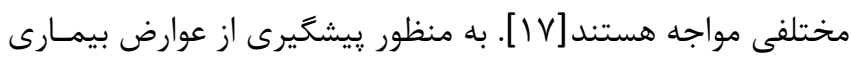


"مستقل بودم" تا اكاملا وابسته هستم/ (در حيطه مراقبت از خود)

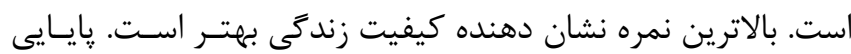

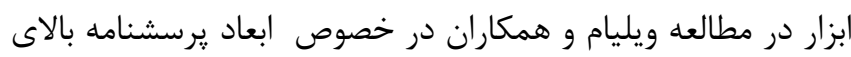

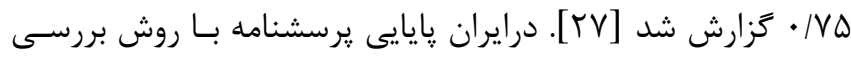

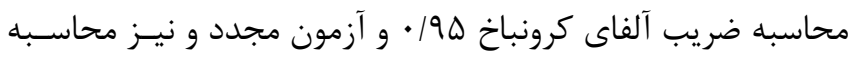

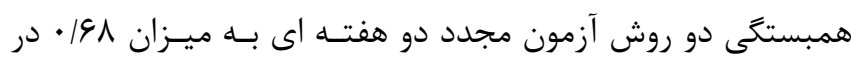

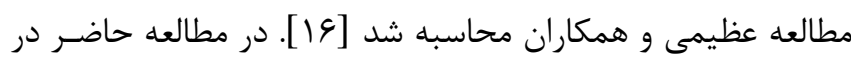

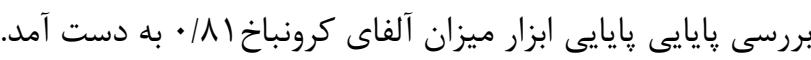

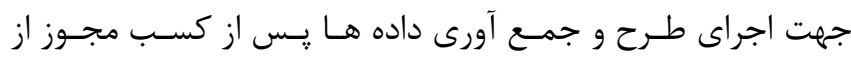

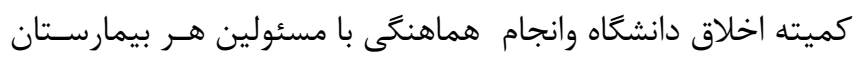

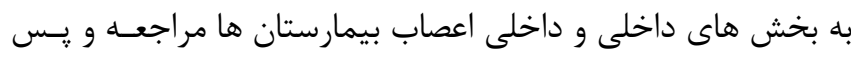

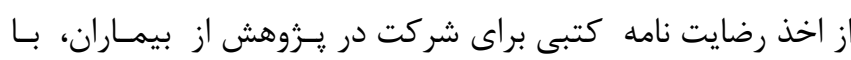

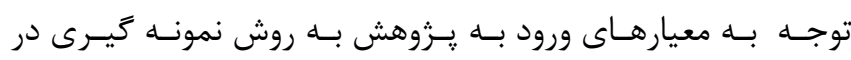

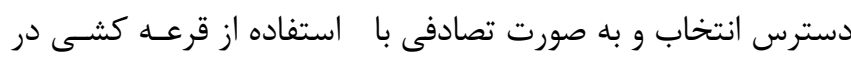

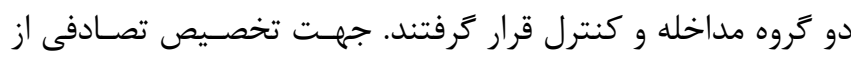

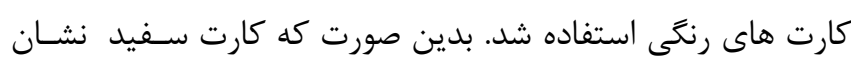

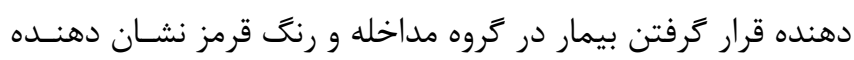

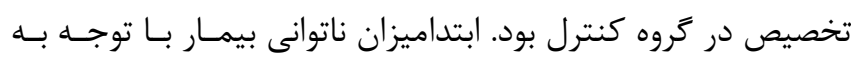

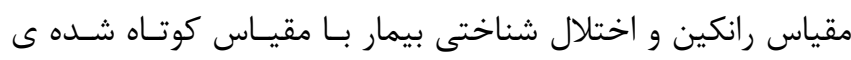

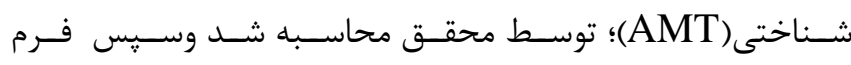

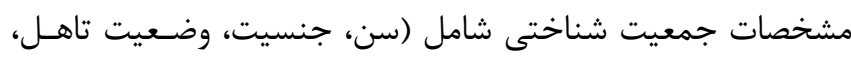
ميزان تحصيلات، شغل و مراقب اصلى بيمار، سابقه بيمارى، مصـرف

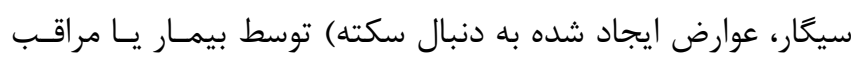

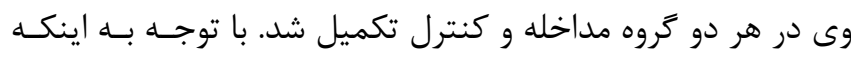
بيماران با تشخيص جديد سكته مغزى در مطالعه مورد بررسى قـرار

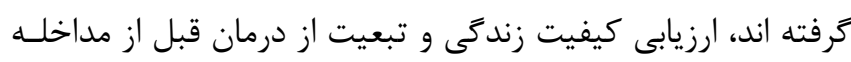

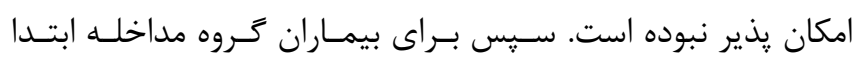

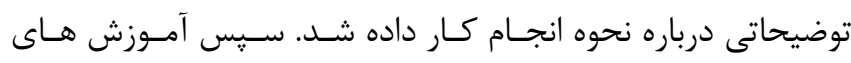

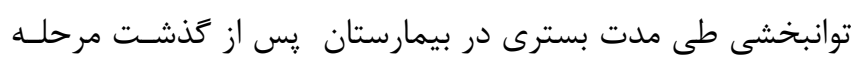

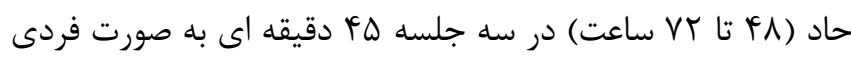

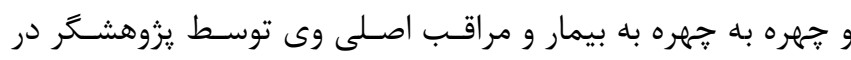

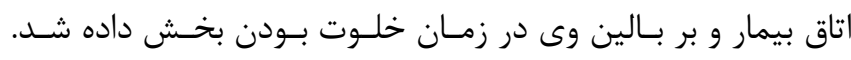

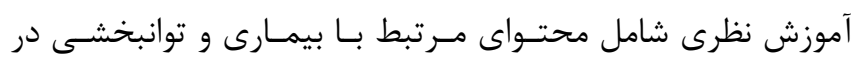
منزل است (جدول ()).

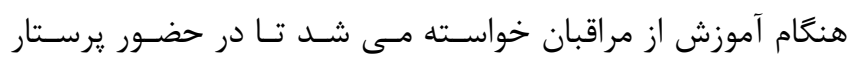
محتواى آموزشى داده شده را تمرين و در طول مدت مرت اقامست بيمـار
عملكردى بيماران به دنبال سكته مغزى كه ناتوانى بيمار از صفر تـا

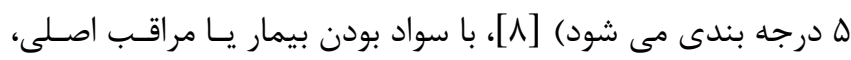

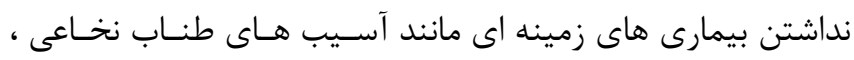

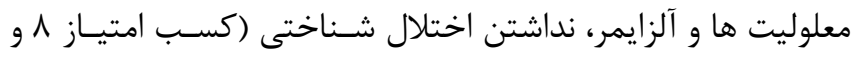

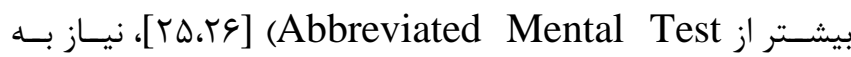

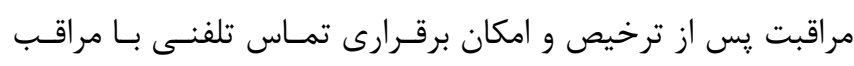

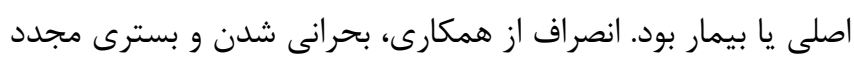

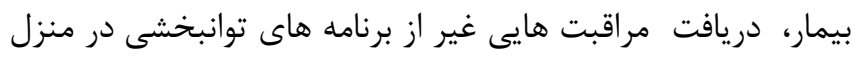

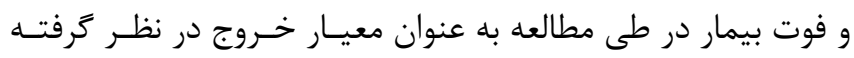

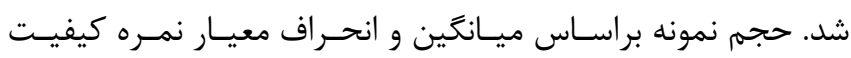

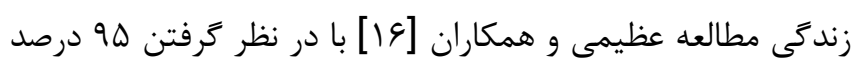

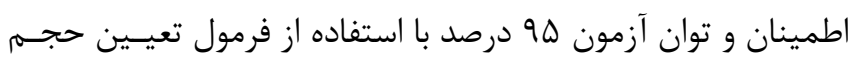

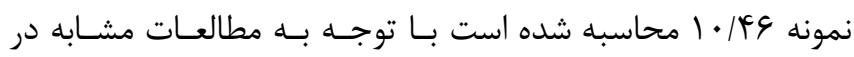

$\mathrm{n}=\frac{\left(Z_{1-\frac{\alpha}{2}}+Z_{1-\beta}\right)^{2}\left(S_{1}{ }^{2}+S_{2}{ }^{2}\right)}{\left(z_{1}-z_{2}\right)^{2}}=1 \cdot / 4 \varphi$ هرگروه •r نفرمنظور شد. $Z_{1-\frac{\alpha}{2}}=1 / 9 \varphi \quad S_{1}=r \psi / \Lambda$ $Z_{1-\beta}=1 / 94$ $S_{2}=r \Delta$ $\overline{X_{1}}=|r 9| \mid$

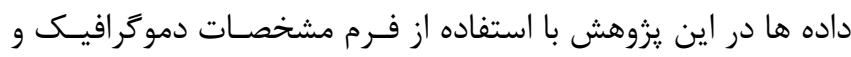

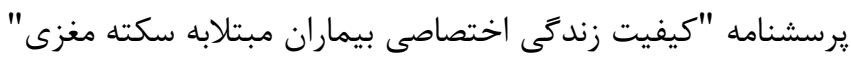

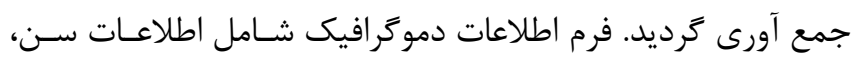

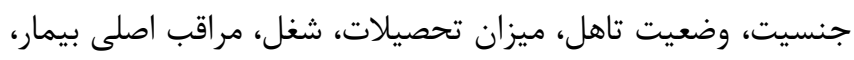

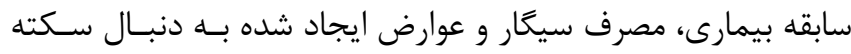

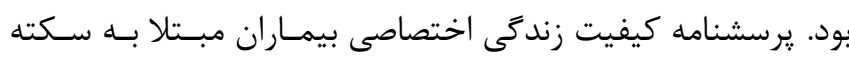

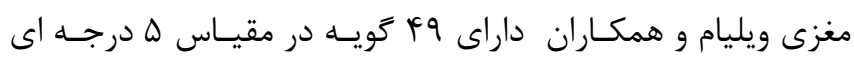

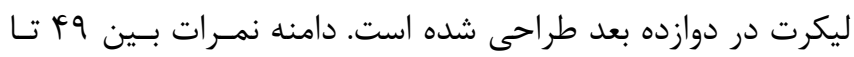

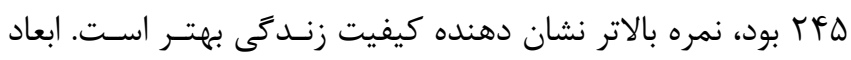

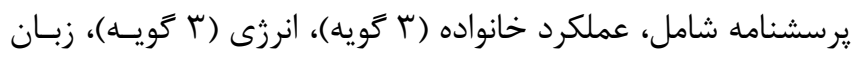

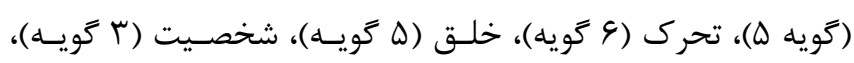

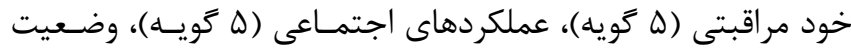

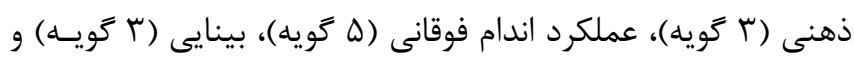

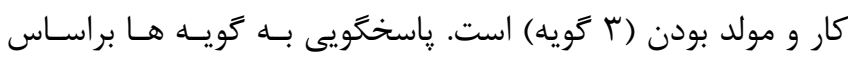

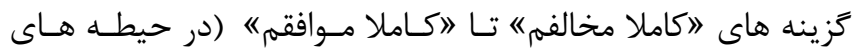

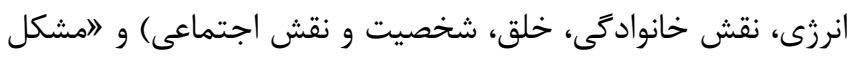

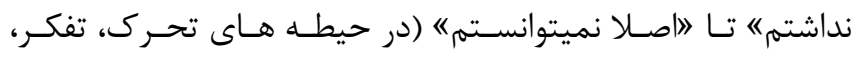

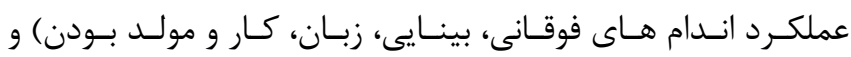




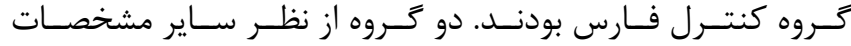

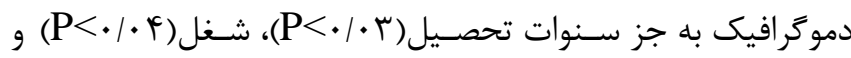

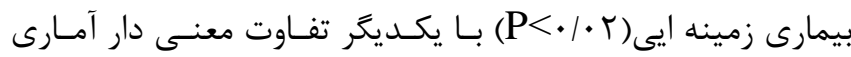
نداشتند (جدول شماره Y). اثر متغيرهاى فردى معنسى دار كنتـرل شد وتنها متغيرمراقب اصلى به طور معنى دار تاثير كذار بود.

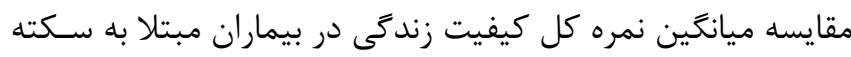

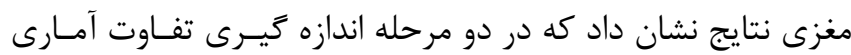

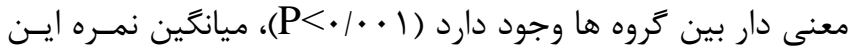

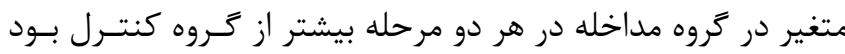

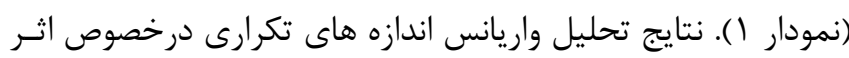
زمان و گروه در كيفيت زندگى بين دو گروه تفاوت معنى دار نشـان

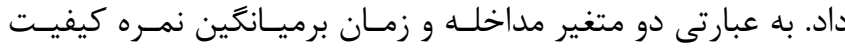

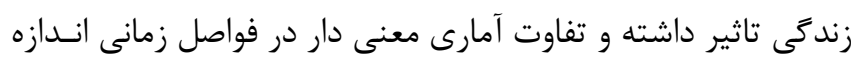

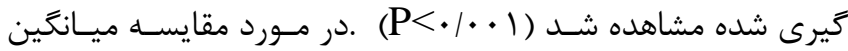
نمرات ابعاد كيفيت زندگى در بيماران مبتلا به سكته مغـزى نتـايج

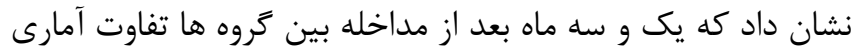

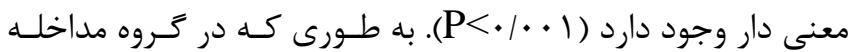

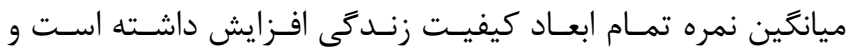

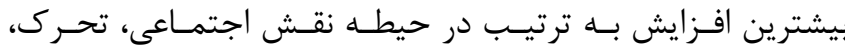

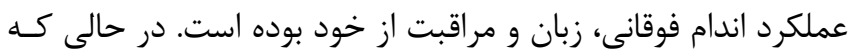

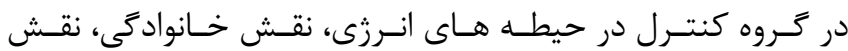

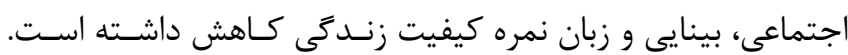

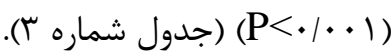

در بيمارستان آن را تكرار و ابهامات احتمـالى را برطـرف نماينـد. از

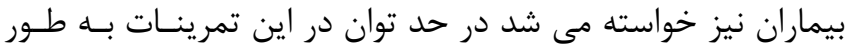

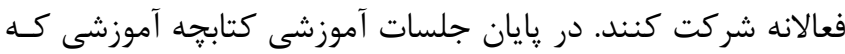
بر اساس متون معتبر علمى زير نظر متخصصان اين حوزه تهيه شده

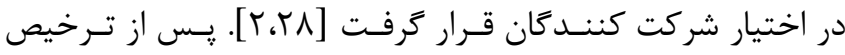

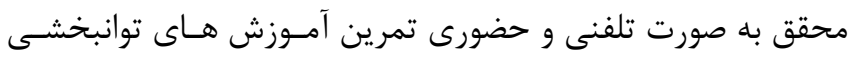

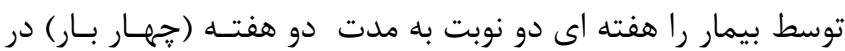

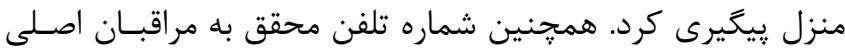

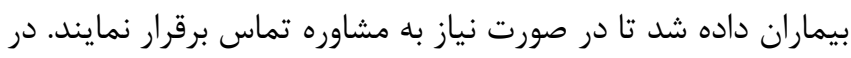

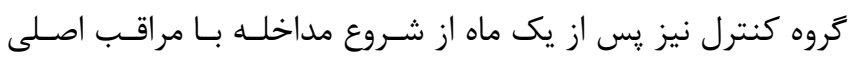

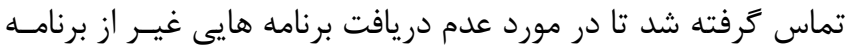

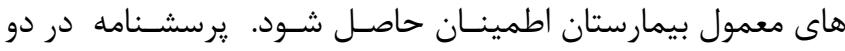
مرحله، يك و سه ماه بعد از اتمام مداخله انجام شده در بيمارستـان

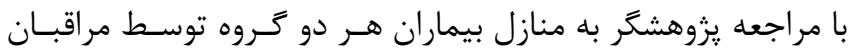
تكميل شد. جهت رعايت نكات اخلاقسى بـهـ كـروه كنتـرل در بايـان

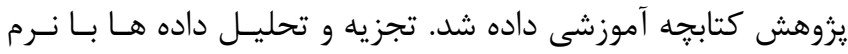
افزار آمارى SPSS نسخه كب و و آزمون هاى آمارى تحليل واريـانس

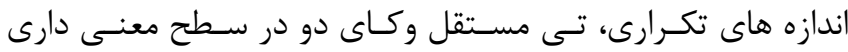

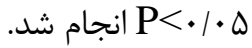

\section{يافتهها}

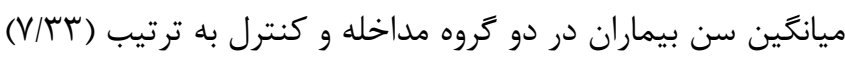

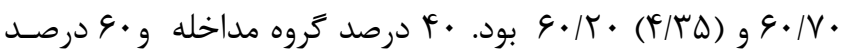

جدول ا: ساختار جلسات و محتواى آموزشى بيماران مبتلا به سكته مغزى

\begin{tabular}{|c|c|}
\hline 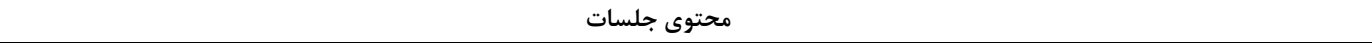 & جلسه \\
\hline آموزش هاى مرتبط با بيمارى و عوامل ايجاد آن، عوارض يس از سكته مغزى، فعاليت بدنى، تغيير يوزيشن، تمرينات دامنه حركتى مفاصل، بهداشت فردى، زخم بستر & اول \\
\hline آموزش هاى مرتبط با رزيم تغذيه اي مناسب، مراقبت هاى حين تغذيه، بهداشت دهان و دندان & 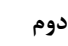 \\
\hline آموزش هاى مرتبط با نوع داروها، نحوه و زمان مصرف دارو، عوارض داروها & سوم \\
\hline
\end{tabular}


جدول r: مشخصات دموكرافيك بيماران مبتلا به سكته مغزى در دو كروه مداخله وكنترل

\begin{tabular}{|c|c|c|c|c|}
\hline نتيجه آزمون & 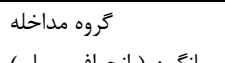 & 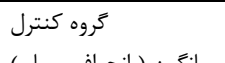 & & \\
\hline & ميانكين ( انحراف معيار ) & ميانكين ( انحراف معيار ) & & \\
\hline$p:=\cdot / V^{q}$ & $4 \cdot / V \cdot(\mathrm{V} / \mathrm{Tr})$ & $G \cdot \pi \cdot(\tau / \pi \Delta)$ & & سن \\
\hline \multirow[t]{2}{*}{$\mathrm{P}^{*}=\cdot / \cdot r$} & $r / \Delta \cdot(T / 19)$ & $\Delta / 1 \cdot(\Delta / \Delta \&)$ & & سنوات تحصيلى \\
\hline & فراوانى (درصد) & فراوانى (درصد) & & \\
\hline \multirow[t]{2}{*}{$\mathrm{p}^{* *}=1$} & $1 \Delta(\Delta \cdot)$ & $10(\Delta \cdot)$ & مونث & جنسيت \\
\hline & $10(\Delta \cdot)$ & $1 \Delta(\Delta \cdot)$ & مذكر & \\
\hline \multirow[t]{2}{*}{$\mathrm{p}^{* *}=\cdot / 1 \mathrm{r}$} & $11(\varphi \cdot)$ & $\operatorname{Ir}(\boldsymbol{r} \cdot)$ & بلوج & ق قوميت \\
\hline & $\mathbb{I r}(\boldsymbol{F} \cdot)$ & $11(9 \cdot)$ & سيستانى & \\
\hline \multirow[t]{2}{*}{$\mathrm{p}^{* *}=\cdot / \cdot{ }^{\kappa}$} & $\mathbb{I r}(\boldsymbol{t} \cdot)$ & $q(r \cdot)$ & شاغل & شغل بيمار \\
\hline & $M(\varphi \cdot)$ & $r I(V \cdot)$ & غير شاغل & \\
\hline \multirow[t]{2}{*}{$P * * \cdot / \cdot r$} & $9(r \cdot)$ & $11(9 \cdot)$ & همسر & مراقب اصلى بيمار \\
\hline & $r I(V \cdot)$ & $\mathbb{I r}(\boldsymbol{F} \cdot)$ & 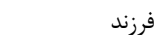 & \\
\hline \multirow[t]{2}{*}{$p^{* *}=\cdot / \cdot r$} & $r I(V \cdot)$ & $r V(q \cdot)$ & دارد & بيمارى زمينه ايى \\
\hline & $9(\% \cdot)$ & $r(1 \cdot)$ & ن ارد & \\
\hline \multirow[t]{2}{*}{$p^{* *}=\cdot / 11$} & $9(r \cdot)$ & $1 \Delta(\Delta \cdot)$ & دارد & مصرف سيخار \\
\hline & $r I(V \cdot)$ & $1 \Delta(\Delta \cdot)$ & ندارد & \\
\hline \multirow[t]{2}{*}{$\mathrm{p}^{* *}=\cdot / \cdot v$} & $9(\Gamma \cdot)$ & $\mathbb{I r}(\boldsymbol{F} \cdot)$ & دوعارضه & عوارض بيمارى \\
\hline & $r)(V \cdot)$ & $11(9 \cdot)$ & بيش از دو عارضه & \\
\hline
\end{tabular}

جدول ז: مقايسه ميانكَين نمرات ابعاد كيفيت زندكى در بيماران مبتلا به سكته مغزى بسترى در يك و سه ماه پِ از مداخله در دو كروه مداخله و كنترل

\begin{tabular}{|c|c|c|c|c|c|}
\hline تحليل واريانس اندازه & نتيجه آزمون تى مستقل & 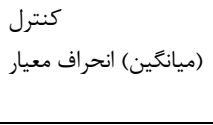 & (ميانگين) انحراف معيار & كروه & ابعاد كيفيت زندَى \\
\hline \multirow[t]{2}{*}{$\mathrm{P}<\cdot / . .1$} & $\mathrm{P}<\cdot / \cdot \cdot 1$ & $V / \Lambda(1 / \cdot 9)$ & $1 \cdot / r(1 / \cdot 9)$ & يك ماه بعد از مداخله & انرزى \\
\hline & $\mathrm{P}<\cdot / \cdot .1$ & $V / F T(1 / Y)$ & $1 \cdot / 99(1 / \Delta 8)$ & سه ماه بعد از مداخله & \\
\hline \multirow[t]{2}{*}{$\mathrm{P}<\cdot / . .1$} & $\mathrm{P}<\cdot / \cdot .1$ & $1 \cdot / \Lambda(1 / T \Lambda)$ & $\mathrm{q} / \mathrm{V}(\mathrm{I} / \mathrm{AV})$ & يك ماه بعداز مداخله & نقش خانوادَىى \\
\hline & $\mathrm{P}<\cdot / \cdot .1$ & $V / \Lambda \&(1 / G \Psi)$ & $11 / \uparrow r(1 / \Delta 9)$ & سه ماه بعد از مداخله & \\
\hline \multirow[t]{2}{*}{$\mathrm{P}<\cdot / . \cdot 1$} & $\mathrm{P}<\cdot / \cdot .1$ & $1 T / T(1 / T 9)$ & $\operatorname{IV} / \mathrm{V}(\mathrm{I} / \mathrm{AV})$ & يك ماه بعداز مداخله & 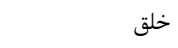 \\
\hline & $\mathrm{P}<\cdot / \cdot .1$ & $|r /| r(\mid / \vee q)$ & 19/94(1/91) & سه ماه بعد از مداخله & \\
\hline \multirow[t]{2}{*}{$\mathrm{P}<\cdot / . .1$} & $\mathrm{P}<\cdot / \cdot .1$ & $V / T(1 / 11)$ & $1 \cdot / \Lambda(\cdot / V \varepsilon)$ & يك ماه بعداز مداخله & شخصيت \\
\hline & $\mathrm{P}<\cdot / \cdot .1$ & $V / \Delta r(1 / T \Delta)$ & $11 / \pi \varphi(1 / / 4)$ & سه ماه بعد از مداخله & \\
\hline \multirow[t]{2}{*}{$\mathrm{P}<\cdot / . \cdot 1$} & $\mathrm{P}<\cdot / \cdot \cdot 1$ & $11 / 9(r)$ & $\mid f(1 / V)$ & يك ماه بعداز مداخله & نقش اجتماعى \\
\hline & $\mathrm{P}<\cdot / \cdot .1$ & $11 / \Delta g(r / \cdot r)$ & $\mid V / r q(T / 1)$ & سه ماه بعد از مداخله & \\
\hline \multirow[t]{2}{*}{$\mathrm{P}<\cdot \cdot \cdot \cdot 1$} & $\mathrm{P}<\cdot 1 \cdot .1$ & $\mid \Delta / V(\Gamma / \varphi \mid)$ & $\mid \Lambda(T / Y \Lambda)$ & يكى ماه بعداز مداخله & تحرى \\
\hline & $\mathrm{P}<\cdot / \cdot \cdot 1$ & $1 Q / V(T / \pi \varphi)$ & $T r / F G(Y / T V)$ & سه ماه بعد از مداخله & \\
\hline \multirow[t]{2}{*}{$\mathrm{P}<\cdot / . \cdot 1$} & $\mathrm{P}<\cdot / . \cdot 1$ & $N / q(1 / F F)$ & $\|(\Gamma / \cdot \Lambda)$ & يك ماه بعداز مداخله & تفكر \\
\hline & $\mathrm{P}<\cdot / \cdot .1$ & $N / q(1 / T F)$ & $\mid r(T / \cdot 9)$ & سه ماه بعد از مداخله & \\
\hline \multirow[t]{2}{*}{$\mathrm{P}<\cdot / . \cdot 1$} & $\mathrm{P}<\cdot / \cdot .1$ & $1 r(1 / A V)$ & $\mid V / f(T / \mid \Delta)$ & يك ماه بعداز مداخله & عملكرد اندام فوقانى \\
\hline & $\mathrm{P}<\cdot 1 \cdot .1$ & $1 \pi / 9(Y / \cdot 1)$ & $r \cdot / \Lambda(T / T S)$ & سه ماه بعد از مداخله & \\
\hline \multirow[t]{2}{*}{$\mathrm{P}<\cdot / . \cdot 1$} & $\mathrm{P}<\cdot \mid \cdot \cdot 1$ & $9 / \wedge(1 / 1 \Lambda)$ & $1 r / 1(1 / r 9)$ & يك ماه بعداز مداخله & بينايى \\
\hline & $\mathrm{P}<\cdot / \cdot \cdot 1$ & $N / D S(I / F T)$ & $\mid r / 9 \Psi(1 / \Delta 9)$ & سه ماه بعد از مداخله & \\
\hline \multirow[t]{2}{*}{$\mathrm{P}<\cdot / . \cdot 1$} & $\mathrm{P}<\cdot 1 \cdot .1$ & $9 / D(\cdot / 94)$ & $9 / 9(1 / 99)$ & يك ماه بعداز مداخله & كار و مولد بودن \\
\hline & $\mathrm{P}<\cdot / . .1$ & $V / 9 T(1 / T \Delta)$ & $11 / V(r / 9 \Lambda)$ & سه ماه بعد از مداخله & \\
\hline
\end{tabular}




\begin{tabular}{|c|c|c|c|c|}
\hline & فتيحه كرمان سارو & & & تاثير توانبخشى در منزل ... \\
\hline \multirow[t]{2}{*}{$\mathrm{P}<\cdot / \cdots 1$} & $\mathrm{P}<\cdot / \cdot \cdot 1$ & $\mid F / T(1 / \xi \varphi)$ & $I V / D(T / \Lambda ⿻)$ & يك ماه بعداز مداخله \\
\hline & $\mathrm{P}<\cdot / \cdot \cdot 1$ & $1 \% / 9(T / \cdot 9)$ & $r \cdot \mid G T(T / r T)$ & سه ماه بعد از مداخله \\
\hline \multirow[t]{2}{*}{$\mathrm{P}<\cdot 1 \cdots 1$} & $\mathrm{P}<\cdot / \cdots 1$ & $1 \cdot / Q(1 / 1 / \Gamma)$ & $1 Q / Q(T / T r)$ & يك ماه بعداز مداخله \\
\hline & $\mathrm{P}<\cdot / \cdot \cdot 1$ & $|r /|(1 / 9)$ & $1 N / \Lambda(\Gamma / \Gamma \Delta)$ & سه ماه بعد از مداخله \\
\hline \multirow[t]{2}{*}{$\mathrm{P}<\cdot / \cdots 1$} & $\mathrm{P}<\cdot / \cdot \cdot 1$ & $\mid r \Delta / \Lambda(1 / \Delta Q)$ & $\mid 9 \psi / \Delta(19 / \cdot r)$ & يكى ماه بعداز مداخله \\
\hline & $\mathrm{P}<\cdot / \cdot \cdot 1$ & $\mid Y G / \mathbb{F} \cdot(T / F \Lambda)$ & $191 / T \&(T \Delta / 1 V)$ & سه ماه بعد از مداخله \\
\hline
\end{tabular}

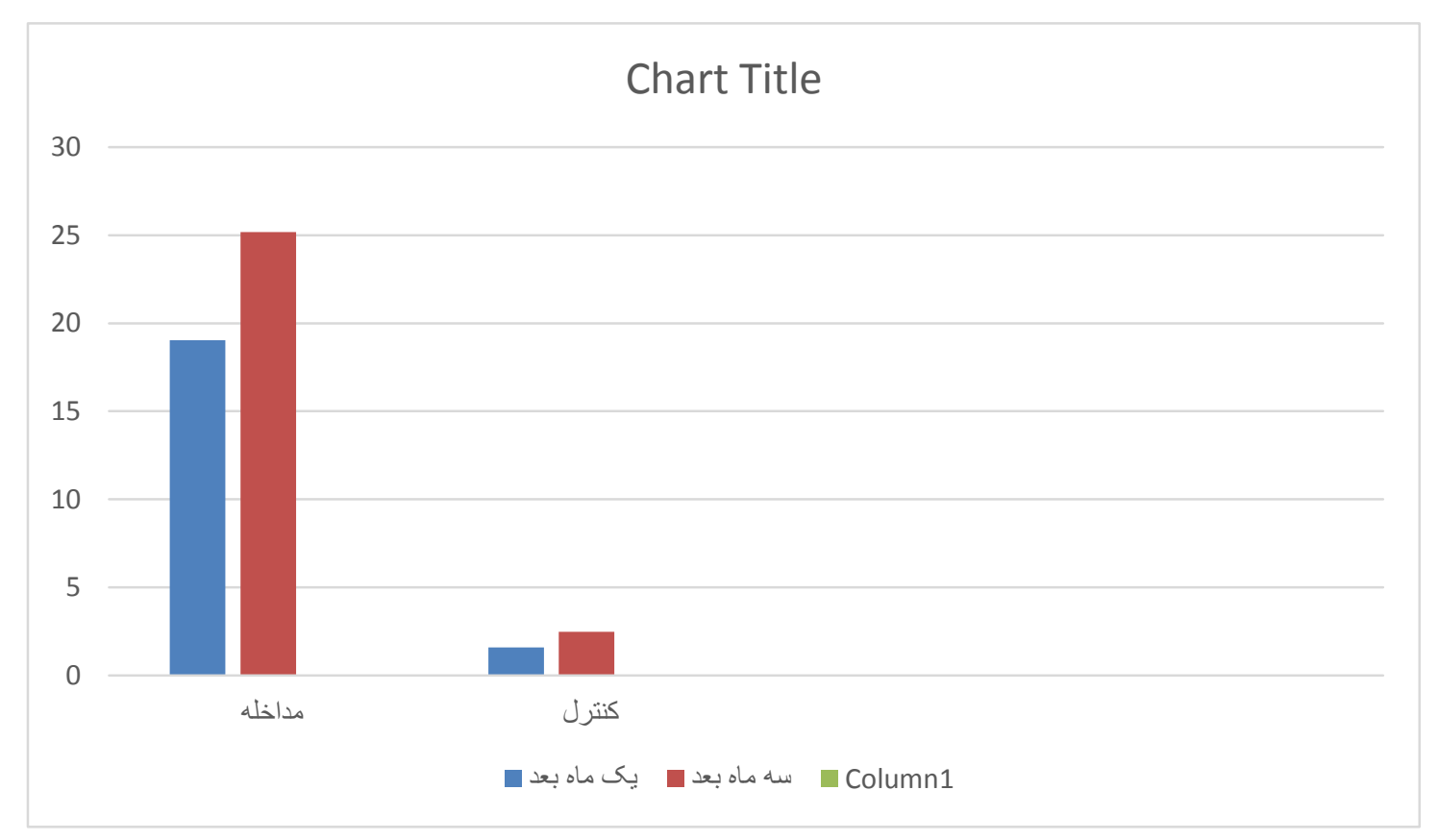

نمودار ا: نمره كل كيفيت زندكى در دو كروه مداخله و كنترل يك و سه ماه بعد از مداخله

ارائه كتابجه آموزشى دانست. در مطالعه Oh تحمل ورزش كردن در بيماران مبتلا به بيمارى مزمن ريوى بعد از اقـدامات توانبخشى در دران

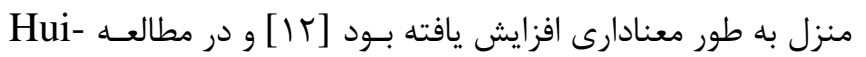

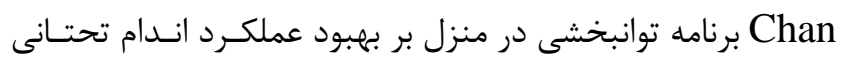

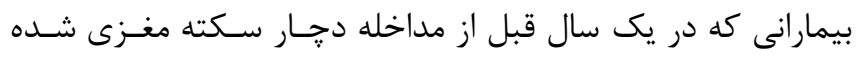

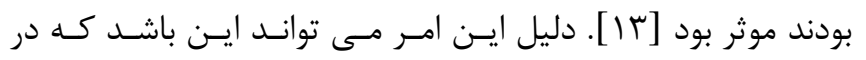

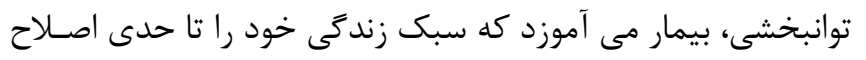

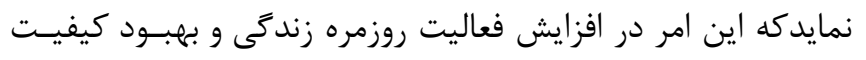

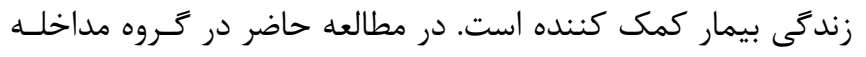

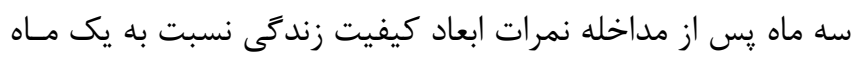

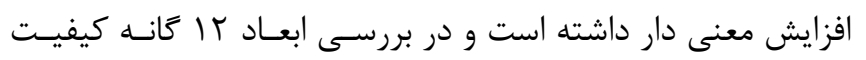

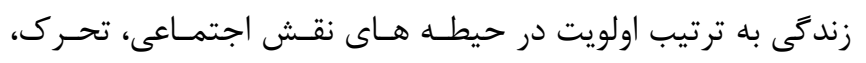

\section{بحث و نتيجه گيرى}

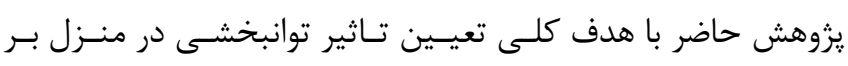

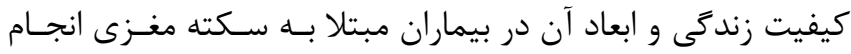

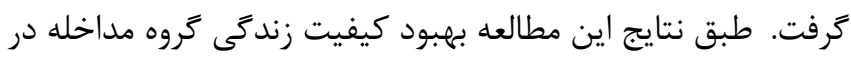

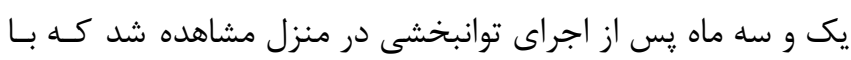

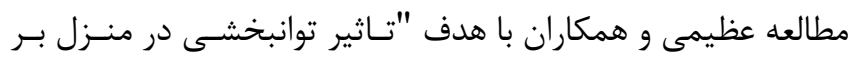

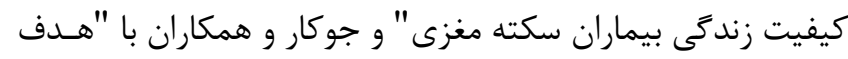

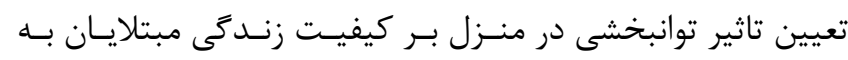

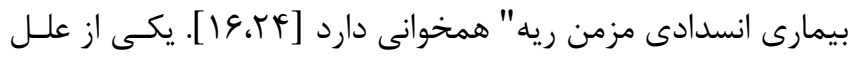

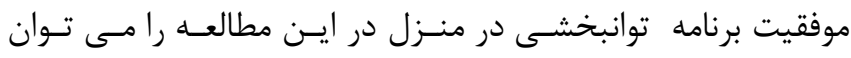

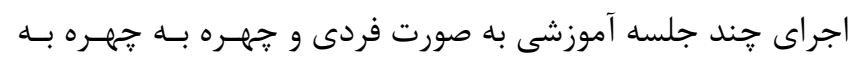

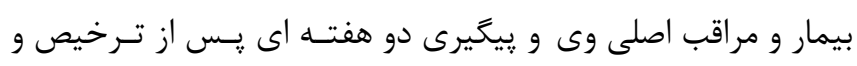


بهبودى بيمار و ارتقاى كيفيـت زنـدكى وى مسى شـود. در مطالعـهـ

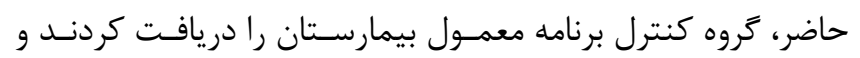

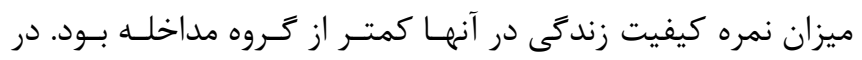

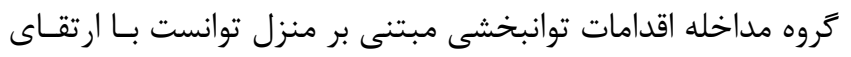

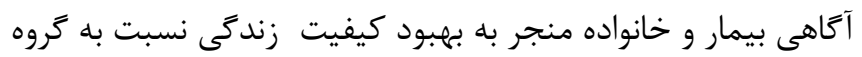

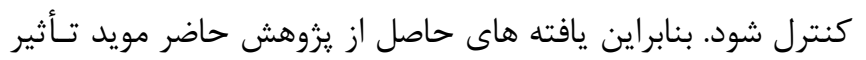

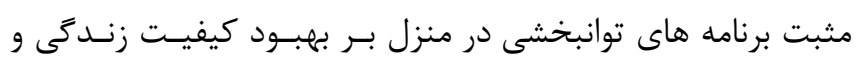

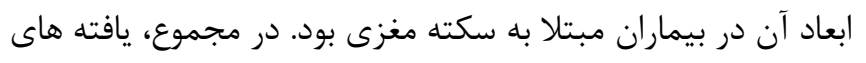

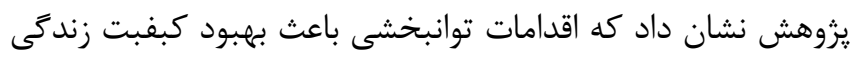

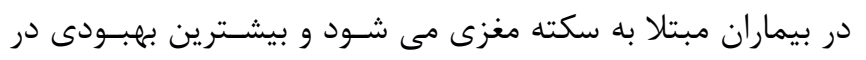

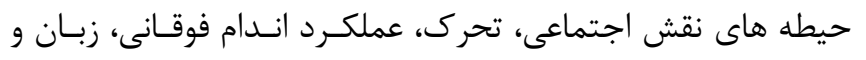

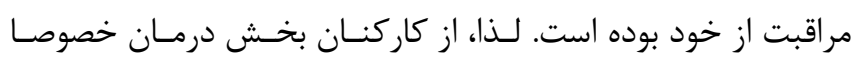

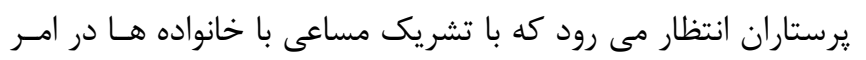

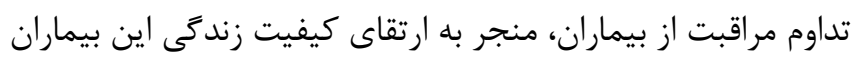

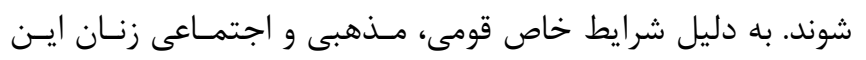

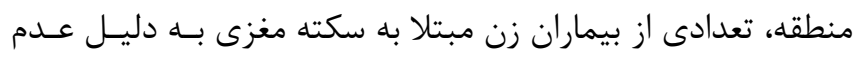

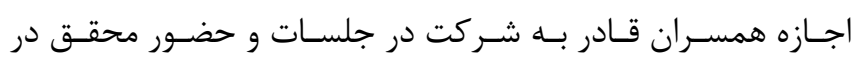

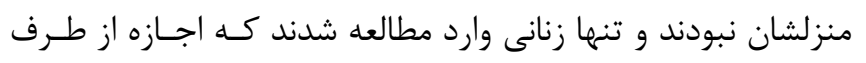

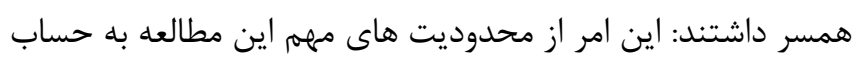

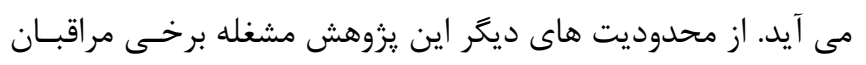

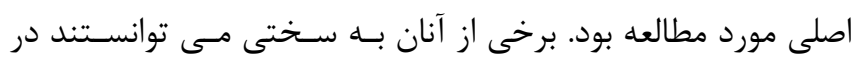

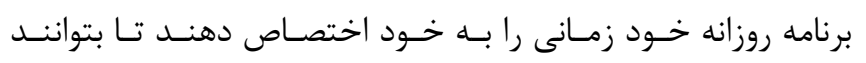
ياسخكوى تماس تلفنى و پِيخيرى آموزش هاى ارايه شده، باشند.

\section{سمم نويسند}

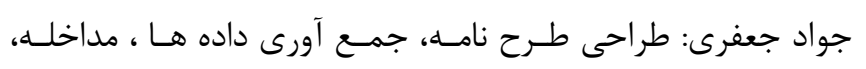
تحليل داده ها، تهيه و تدوين مقاله

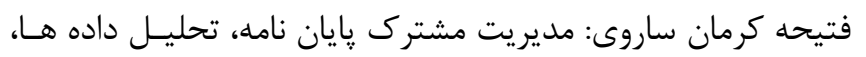
مشاركت در تهيه مقاله

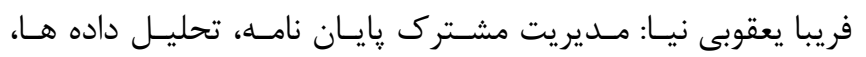
مشاركت در تهيه مقاله

\section{تشكر و قدردانى}

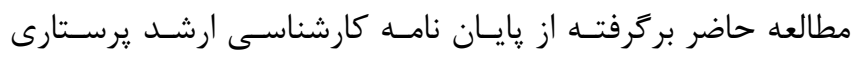

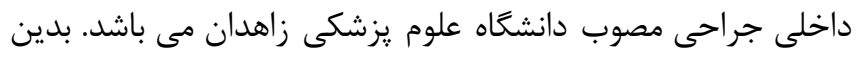

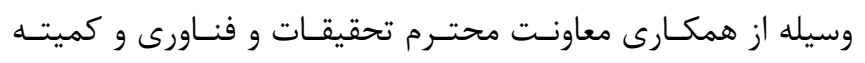

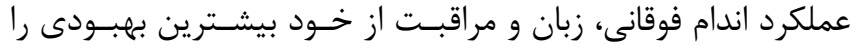

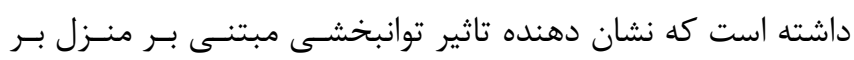

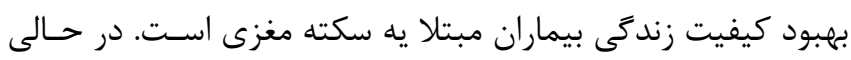

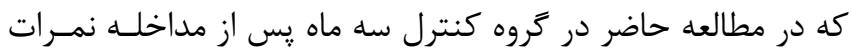

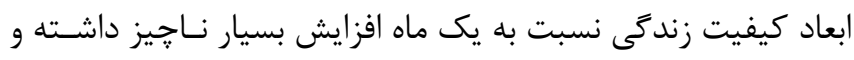

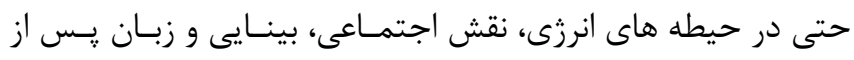

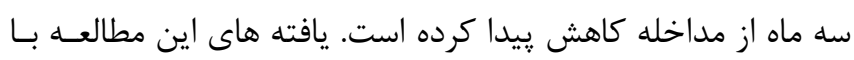

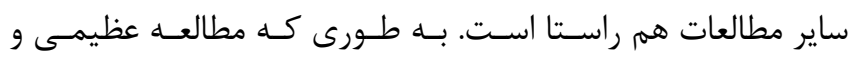

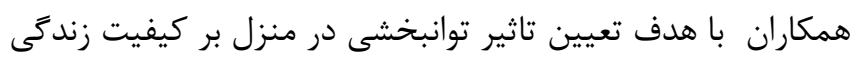

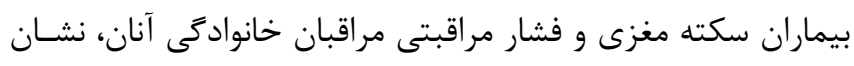

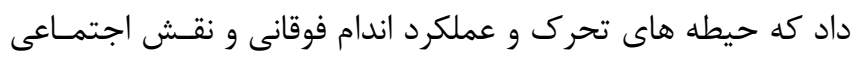

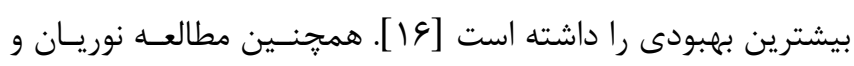

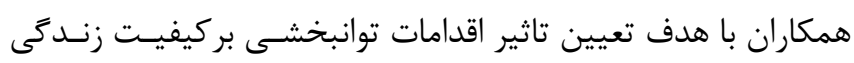

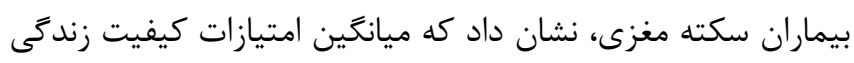

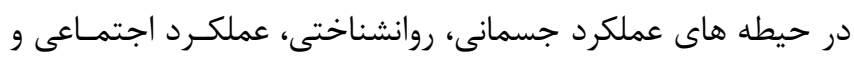

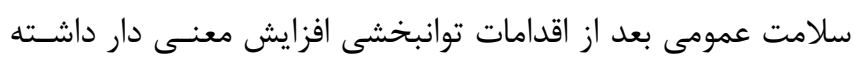

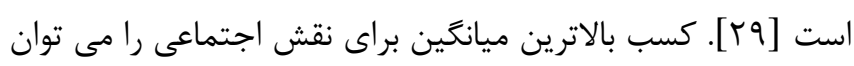

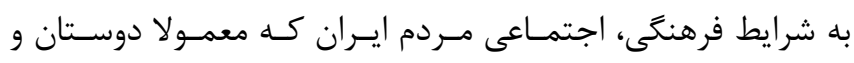

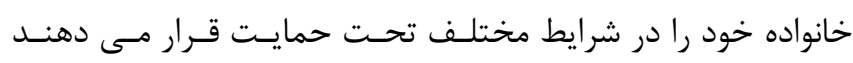

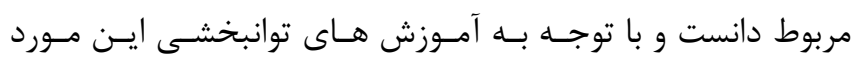

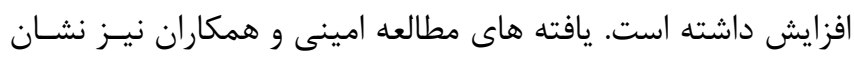

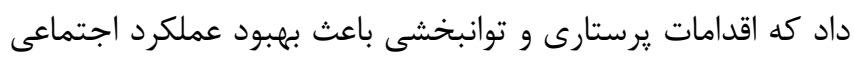

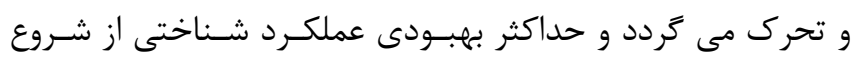

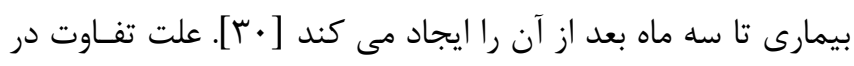

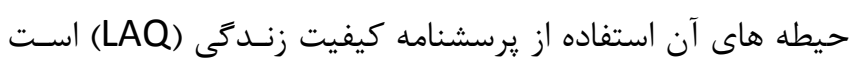

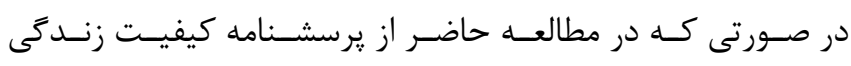

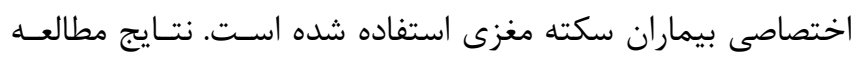
Gbiri

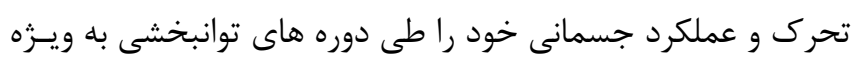

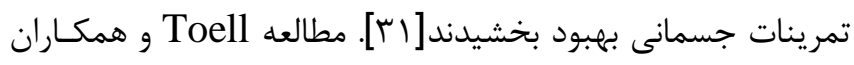

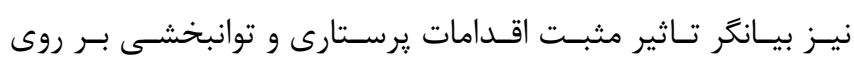

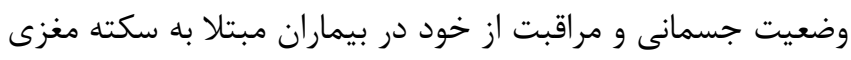

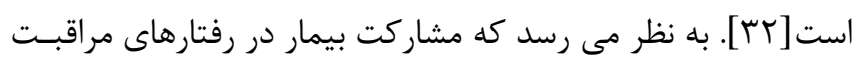

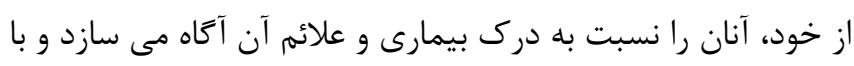

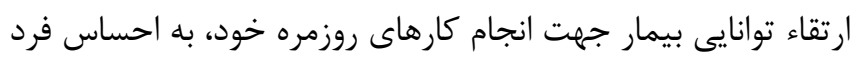
در مورد آينده اش كمك مى نمايد و باعث افزايش اعتماد به نفاء نفس و 


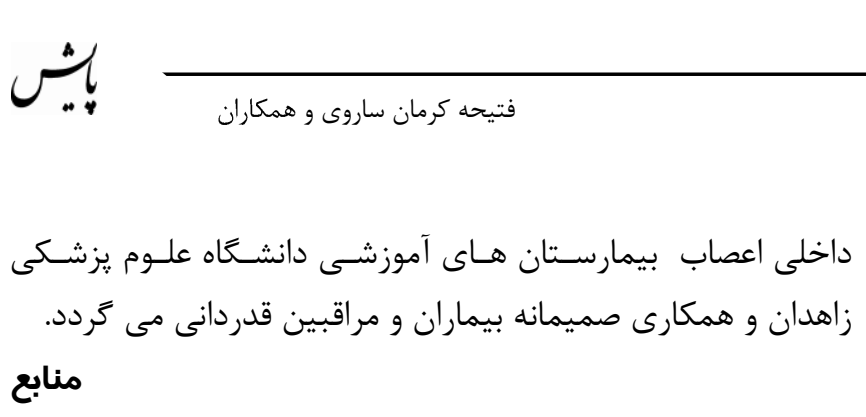

1. Philp I, Brainin M, Walker M, Ward A, Gillard P, Shields A. Development of a Poststroke Checklist to Standardize Follow-up Care for Stroke Survivors. Journal of Stroke Cerebrovascular 2013; 22: 173-180

2. Hinkle J, Cheever K. Brunner \& Suddarths Textbook of Medical-Surgical Nursing. $14^{\text {th }}$ Edition, American: Wolters Kluwer; 2018

3. Pendleton H, Schultz-Krohn W. Pedretti's Occupational Therapy: Practice Skills for Physical Dysfunction. $8^{\text {th }}$ Edition, United States: Elsevier Health Sciences; 2018

4. World Health Organization. Cerebral Stroks. 2018 [Available from: www.who.int/strok/publications/global_health.pdf] 5. Shyam P, Ilana R, Richard A. Acute Stroke Intervention; A Systematic Review. JAMA 2015;313:1451-1462

6. Salarimehr S, Heydari M, Jalilian H, Imani A. Assessing the Quality of Life Among Stroke Patients in Reza Hospital in Tabriz City. Depiction of Health 2018; 9:14-22 [Persian]

7. Tink M, Kessler M. Neurologic Intervention for Physical Therapist Assistants 2015 [Available from: http://books.google.com]

8. Dehghan Nayeri N, Mohammadi S, Pedram Razi S, Arazi T, Kazemnejad A. Effectiveness of Family Empowerment Program on Level of Adherence to Treatment Regimens in Stroke Patients; a Randomized Controlled Trial. Evidence-based Care Journal 2015; 5:57-66 [Persian]

9. Gurbuz N, Afsar SI, Ayaş S, Saracgil-Cosar SN. Effect of Mirror Therapy on Upper Extremity Motor Function in Stroke Patients: a Randomized Controlled Trial. Journal of Physical Therapy Science 2016; 28: 2501-2506

10. Shyu Y, Chen M, Chen S, Wang H, Shao J. A Family Caregiver Oriented Discharge Planning Program for Older Stroke Patients and their Family Caregivers. Journal of Clinical Nursing 2008; 17:2497-2508

11. Chien W-T, Chiu Y, Lam L-W, Ip W-Y. Effects of a Needs-Based Education Programme for Family Carers with a Relative in an Intensive Care Unit: a Quasi-Experimental Study. International Journal of Nursing Studies 2006; 43:39-50

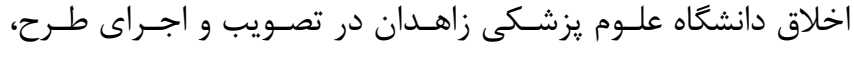

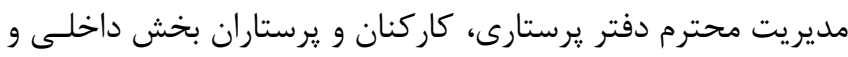

12. Oh G. The Effects of Home-Based Pulmonary Rehabilitation in Patients with Chronic Lung Disease. International Journal of Nursing Studies 2003; 40:873879

13. Hui-Chan C. Effectiveness of a Home-Based Rehabilitation Program on Lower Limb Functions after Stroke Hong Kong. Chinese Medical Journal 2009; 15:42-46

14. Laurent K, De Se`ze M, Delleci C, Koleck N. Assessment of Quality of Life in Stroke Patients with Hemiplegia. Annals of Physical and Rehabilitation Medicine 2011; 54:376-390

15. Pourshirvani A, Abed Saieedi J, Nekozad N, Zandi M. The Impact of Home Care Based on the Continuous Care Model by Family Caregivers on Activities of Daily Living of Stroke Patients. School of Allied Medical Sciences, Shahid Beheshti Univercity 2015; 26:61-73 [Persian]

16. Azimi R, Mohammadi F, Hosseini M, Farzi M. The Effect of Home-Based Stroke Rehabilitation on Quality of Life of Stroke Survivors and Their Family Caregiver's Strain. Evidence-based Care Journal 2013; 3:76-85 [Persian]

17. Mendis S. Stroke Disability and Rehabilition of Stroke: World Health Organization Perspective. International Journal of Stroke 2013; 8:3-4

18. Taheri Tanjani P, Azadbakht M. Psychometric Properties of the Persian Version of the Activities of Daily Living Scale and Instrumental Activities of Daily Living Scale in elderly. Journal of Mazandaran University of Medical Sciences 2015; 25:103-112 [Persian]

19. Dalvandi A, HeikkilA K, Maddah S, Khankeh H, Ekman S. Life Experiences after Stroke Among Iranian Stroke Survivors. International Nursing Review 2010; 57:247-253 [Persian]

20. Lynch E, Butt Z, Heinemann A, Victorson D, Nowinski C, Perez L. Qualitative Study of Quality of Life after Stroke: The Importance of Social Relationships. Journal of Rehabilitation Medicine 2008; 40:23-7

21. Sanaie N, Nejati S, Zolfaghari M, Alhani F, Kazemnezhad A. The Effects of Family-based Empowerment on Family Cooperation in Following Patient Treatment Regime after Coroner Arteries Bypass Surgery: Modern Care. Scientific Quarterly of 
Birjand Nursing and Midwifery Faculty 2014; 11:1927 [Persian]

22. Jafari M, Dalvandi A. Quality of Life of Stroke Survivors and its Related Factors. Iran Journal of Nursing 2014; 27:14-22 [Persian]

23. Johnson C, Lane H, Barber A, Charleston A. Medication Compliance in Ischaemic Stroke Patientsim. Royal Australasian College of Physicians 2010: 47-52

24. Jokar Z, Mohammadi F, Khankeh H, Rabee Z, Falah Tafti S. Effect of Home-Based Pulmonary Rehabilitation on Daily Activity of Patients with Chronic Obstructive Pulmonary Disease. Journal of Evidence-based Care 2014; 4:69-76 [Persian]

25. Hodkinson HM. Evaluation of a Mental Test Score for Assessment of Mental Impairment in the Elderly. Age Ageing 1972; 1: 233-238

26. Bakhtiyari F, Foroughan M, Fakhrzadeh H, Nazari $\mathrm{N}$, Najafi B. Validation of the Persion Version of Abbreviated Mental Test (AMT) in Elderly Resident of Kahrizak Charity Foundation. Iranian journal of Diabetes and Metabolism (Elderly Health Research Center, Special Issue) 2014; 13:487-494 [Persian]
27. Williams LS, Weinberger M, Harris LE, Clark DO, Biller J. Development of a Stroke-Specifc Quality ofLife Scale. Stroke 1999; 30:1362-1369

28. Black B. Professional Nursing. $8^{\text {th }}$ Edition, Philadelphia: Elsevier; 2018

29. Nurian K, Kazemian A, Aslani U, Delaram M. Effectiveness of Rehabilitation Program on Quality of Life of Stroke Survivors. Zanjan Medical University 2005; 13: 22-27 [Persian]

30. Amini $\mathrm{P}$, Khalilzadeh $\mathrm{H}$, Hemmati M, Kohankari M, Mirmohammadi A, Haghshenas A. Investigation of Nursing Intervention and Rehabilitation Programs on Life Quality of Hospitalized Patients with Stroke. Quarterly Journal of the School of Nursing and Midwifery 2006;3:1-7 [Persian]

31. Gbiri CA, Akinpelu AO. Quality of life of Nigerian Stroke Survivors During First 12 Months Post-Stroke. Hong Kong Physiotherapy Journal 2012;30;18-24

32. Toell $\mathrm{T}$, Boehme $\mathrm{C}$, Mayer L, Krebs S, et al. Pragmatic Trial of Multifaceted Intervention (STROKE-CARD care) to Reduce Cardiovascular Risk and Improve Quality-of-Life after Ischemic Stroke and Transient Ischemic Attack -Study Protocol. BMC Neurology 2018; 18:187 